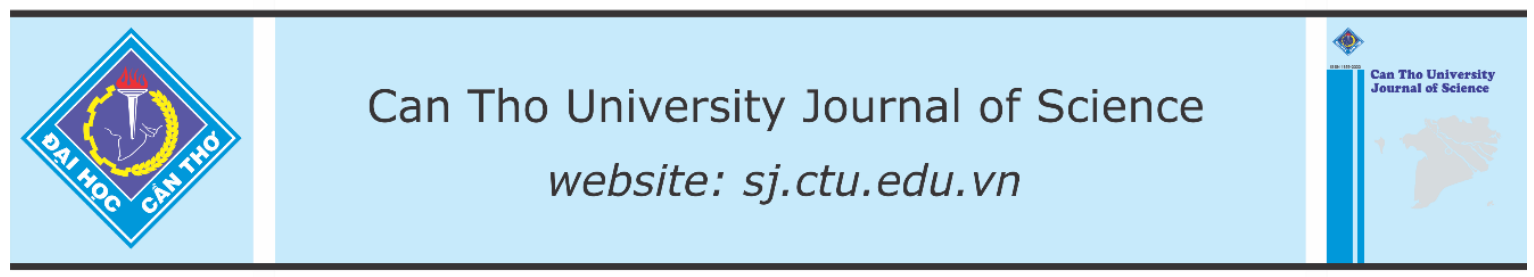

DOI: 10.22144/ctu.jen.2020.007

\title{
Optimization of condition for pectin extraction from pomelo peel using response surface methodology
}

\author{
Nguyen Thi Lan Phi ${ }^{1,2 *}$, Nguyen Duong Phuoc Tuan ${ }^{2,3}$, Tan Hoang Nam ${ }^{2,3}$ and Pham Van Hung ${ }^{2,3}$ \\ ${ }^{I}$ Department of Food Technology, International University, Ho Chi Minh city, Vietnam \\ ${ }^{2}$ Vietnam National University, Ho Chi Minh city, Vietnam \\ ${ }^{3}$ Department of Food Technology, University of Technology, Ho Chi Minh City, Vietnam \\ *Correspondence: Nguyen Thi Lan Phi (email:nglanphi@gmail.com)
}

\section{Article info.}

Received 27 Nov 2019

Revised 01 Mar 2020

Accepted 31 Mar 2020

\section{Keywords}

Pectin, pomelo peel, response surface methodology, ultrasound-assisted extraction

\begin{abstract}
The objective of this study was to optimize extraction condition of pectin from the pomelo peel based on the ultrasound-assisted extraction method using response surface methodology. The effect of four independent variables: solid/liquid ratio $(1 / 30,1 / 40,1 / 50 \mathrm{~g} / \mathrm{mL}), \mathrm{pH}$ values of citric acid ( $\mathrm{pH}$ 1.5 - 2.5), sonication time (30 - $50 \mathrm{~min}$ ) and extraction temperature (60 $80^{\circ} \mathrm{C}$ ) on the yield of pectin extracted from Da Xanh pomelo pomace was analyzed using Box-Behnken design. The high coefficient of determination value $\left(R^{2}=0.9299\right)$ indicated that the experimental data were fitted to a second order polynomial equation using multiple regression analysis. The model was highly significant because the model F-value was 11.37 with low p-value $(p<0.0001)$. Therefore, the model could be employed to optimize the extraction process. Optimal experimental extraction condition for the highest pectin yield from pomelo peel (12.4\%) was obtained with the solid/liquid ratio of $1 / 49.5 \mathrm{~g} / \mathrm{mL}$, $\mathrm{pH}$ of citric acid of 1.5 , sonication time of $47 \mathrm{~min}$ and temperature of $78^{\circ} \mathrm{C}$. The results obtained from validation experiments were consistent with the predicted data.
\end{abstract}

Cited as: Phi, N.T.L., Tuan, N.D.P., Nam, T.H. and Hung, P.V., 2020. Optimization of condition for pectin extraction from pomelo peel using response surface methodology. Can Tho University Journal of Science. 12(1): 50-57.

\section{INTRODUCTION}

Pomelo (Citrus grandis L.), a member of the genus Citrus, belongs to the family Rutaceae (Paudyal and Haq, 2008). Inside the thick crust of the fruit is the spongy white peel layer, which is considered as a good source of pectin, accounting for up to $30 \%$ of the total fruit weight (Quoc et al., 2015). Hot and humid climate is the best condition for the growth of pomelo. As a result, pomelo can be found mostly in the Southeast Asia, especially in Vietnam, Indonesia, and Thailand. Pectin is complex heteropolysaccharide which presents in the cell wall of higher plants and is distributed mainly in parts such as fruits, tubers, and stalks of the plant. Chemically, these polysaccharides are formed mostly by linear polymers that are rich in galacturonic acid (GalA), participating in the polymer chains by $\alpha-(1-4)$ glycosidic linkage (Talmadge et al., 1973; Knee et al., 1975). Pectin is predominant in citrus fruits and apple peels (Fox, 1984; Canteri-Schemin et al., 2005). 
The highest concentration of pectin in the cell wall can be found mostly in the middle lamella, primary cell and secondary walls with a gradual decrease from the primary cell wall toward the plasma membrane (Jarvis, 1984). Pectin is widely used as a functional ingredient in food industry as gelling, stabilizing and thickening agent because of their ability to form gels and coagulation products such as jams, jellies, fruit juice, ice-cream, yogurts, and several fermented dairy products.

Response surface methodology (RSM) is a collection of mathematical and statistical techniques that describe the behavior of a data set with the objective of making statistical previsions based on the fit of a polynomial equation to the experiment data. The main objective of RSM is to simultaneously optimize the levels of these variables, determine the optimum operational conditions to obtain the desirable response (Bezerra et al., 2008). Box-Behnken designs (BBDs) are a class of rotatable or nearly rotatable second-order designs based on three level incomplete factorial designs (Ferreira et al., 2007). The efficient analysis of the first and second order coefficients of the mathematical model is obtained by choosing points from the three level factorial arrangements based on the BBDs. In BBDs, the experimental points are located on a hyper sphere equidistant from the central point (Bezerra et al., 2008).

Studies involving pectin extraction methods are numerous (Methacanon et al., 2014; Venzon et al., 2015). In traditional extraction methods, pectin is extracted using organic or inorganic acids at low $\mathrm{pH}$ under high temperature, which is environmental unfriendly and expensive. Recently, ultrasound-assisted extraction method has been used as an effective method for extraction from with increased yield, saved energy and reduced extraction time (Bagherian et al., 2011). However, little information of application of ultrasound-assisted extraction method for pectin extraction from pomelo peels. Therefore, the objective of this study was to optimize conditions of the ultrasound-assisted extraction method and citric acid as solvent for extracting pectin from the pomelo peel using response surface methodology. The extraction conditions were optimized to investigate the effect of four independent variables: solid/liquid ratio, $\mathrm{pH}$ values of citric acid, sonication time and sonication temperature on the yield of pectin extracted from $\mathrm{Da}$ Xanh pomelo pomace.

\section{MATERIALS AND METHODS}

\subsection{Materials}

The fresh pomelos named Da Xanh pomelo were bought from the wholesale market in Dong Nai province, Vietnam. All fruits were approximate uniformity of shape and size, ripeness and did not contain any contaminations. After collecting and washing, the pomelo peels were peeled off, and then the spongy white part of peels was collected by separating from the green parts of peels. The spongy white peels were cut into small cubic pieces $(1.0 \times 1.0 \times$ $1.0 \mathrm{~cm}^{3}$ ) and then those pieces were subjected to a bleaching process by heating in boiling water for 3 min. After cooling in an ice-bath, the spongy pieces were dried in a force-draft oven at approximately $55^{\circ} \mathrm{C}$ overnight until the moisture content of the peels was about $10-12 \%$. The dried pieces were then ground, sieved to get the fine powder and store in a desiccator before transferring to the extraction step.

\subsection{Ultrasound-assisted extraction of pectin (UAE)}

The UAE was performed in an ultrasonic cleaning bath (WUC-A10H, Daihan Co.). A mixture of pomelo powder and citric acid at different ratios $(1 / 30$, $1 / 40,1 / 50 \mathrm{~g} / \mathrm{mL}$ ) was adjusted to different $\mathrm{pH}$ values $(1.5-2.5)$ and exposed the ultrasound at different temperatures $\left(60-80^{\circ} \mathrm{C}\right)$ for different sonication time (30 - $50 \mathrm{~min})$. After extraction, the mixture was filtered by filter paper to remove any insoluble materials. The filtrate was coagulated using $95 \%$ ethanol equal volume under $4^{\circ} \mathrm{C}$ for $2 \mathrm{hrs}$. Then the coagulated pectin was filtered and washed three times with $95 \%$ ethanol before drying at the temperature of $40^{\circ} \mathrm{C}$ for $24 \mathrm{hrs}$.

\subsection{Box-Behnken experimental design}

The extraction conditions were optimized using RSM. Three levels of four variables of BBD were used to evaluate the main and interaction effects of the factors $\mathrm{X}_{1}$ (solid/liquid ratio), $\mathrm{X}_{2}(\mathrm{pH}$ of citric acid), $\mathrm{X}_{3}$ (sonication time) and $\mathrm{X}_{4}$ (sonication temperature) on the pectin yield, in which each factor was given at three levels, coded $-1,0$ and +1 for low, middle and high values, respectively (Table 1). 
Table 1: Symbols and coded levels of four variables chosen for BBD

\begin{tabular}{lrrr}
\hline \multirow{2}{*}{ Independent variables } & \multicolumn{3}{c}{ Coded Level } \\
\cline { 2 - 4 } & \multicolumn{1}{c}{$\mathbf{- 1}$} & $\mathbf{0}$ & $\mathbf{1}$ \\
\hline $\mathrm{X}_{1}($ Solid/liquid ratio) & $1 / 30$ & $1 / 40$ & $1 / 50$ \\
$\mathrm{X}_{2}(\mathrm{pH})$ & 1.5 & 2 & 2.5 \\
$\mathrm{X}_{3}$ (Sonication time) & 30 & 40 & 50 \\
$\mathrm{X}_{4}$ (Sonication temperature) & 60 & 70 & 80 \\
\hline
\end{tabular}

Four significant independent variables, $\mathrm{X}_{1}, \mathrm{X}_{2}, \mathrm{X}_{3}$ and $\mathrm{X}_{4}$ were used in this system and the mathematical relationship of the response on these variables was approximated by the second-order polynomial equation:

$Y \%=\beta_{0}+\beta_{1} X_{1}+\beta_{2} X_{2}+\beta_{3} X_{3}+\beta_{4} X_{4}+\beta_{12} X_{1} X_{2}+$ $\beta_{13} X_{1} X_{3}+\beta_{14} X_{1} X_{4}+\beta_{23} X_{2} X_{3}+\beta_{24} X_{2} X_{4}+\beta_{34} X_{3} X_{4}$ $+\beta_{11} X_{1}^{2}+\beta_{22} X_{2}^{2}+\beta_{33} X_{3}^{2}+\beta_{44} X_{4}^{2}(1)$

In which, $\mathrm{Y}$ is the estimated response $(\%) ; \beta_{0}$ is the constant, $\beta_{1}, \beta_{2}, \beta_{3}$ and $\beta_{4}$ are linear coefficients; $X_{1}$, $X_{2}, X_{3}$ and $X_{4}$ are independent variables; $\beta_{12}, \beta_{13}$, $\beta_{14}, \beta_{23}, \beta_{24}$ and $\beta_{34}$ are interaction coefficients between the three factors; $\beta_{11}, \beta_{22}, \beta_{33}$ and $\beta_{44}$ are quadratic coefficients.

\subsection{Optimization}

The optimization of the extraction process was done by the Design-Expert software (Trial version 11, Stat-Ease Inc., USA). After optimization, the confirmatory experiments were carried out under the optimal conditions obtained by desirability function methodology. The validity of the developed response model was evaluated by comparing the confirmatory result with the value predicted from the model.

\subsection{Determination yield of pectin $(\% \mathrm{Y})$}

Pectin of the spongy white peel was extracted with citric acid as an effectively extractable solvent according to the method of Venzon et al. (2015) with a slight modification. The dried peel powder $(50 \mathrm{~g})$ was mixed with citric acid solution according to the extraction conditions including solid/liquid ratio $(1 / 30,1 / 40,1 / 50 \mathrm{~g} / \mathrm{mL}), \mathrm{pH}$ values of citric acid $(\mathrm{pH}$ 1.5 - 2.5), sonication time (30 - $50 \mathrm{~min})$ and extraction temperature $\left(60-80^{\circ} \mathrm{C}\right)$, as shown in Table 2 . The suspension was then boiled at $90^{\circ} \mathrm{C}$ for $90 \mathrm{~min}$. After cooling, the suspension was filtered through silk cloth followed by centrifugation to remove solid residues. The obtained filtrate was mixed with pure ethanol at a ratio of 1:2(v/v) and kept overnight to obtain the precipitation of pectin. Then, the precipitate was separated by centrifugation and washed with ethanol twice before drying at $50^{\circ} \mathrm{C}$. The dried extracted pectin was then ground and stored in the desiccator until analysis.

The yield of pectin was calculated based on dry basis by the equation is shown below (Venzon et al., 2015):

$$
\% Y=\frac{\text { Mpectin }}{\text { Mraw }} \times 100
$$

Where, $\mathbf{M}_{\text {pectin }}$ is the pectin mass obtained $\mathrm{M}_{\mathrm{raw}}$ is the raw material utilized for extraction

\subsection{Statistical analysis}

These statistical analyses will perform using the Design-Expert software (Trial version 11, Stat-Ease Inc., USA). The modeling was started with a quadratic model including linear, squared, and interaction terms. Significant terms in the model for each response were found by analysis of variance (ANOVA), and significance is judged by the F-statistic calculated from the data. The experimental data was evaluated with various descriptive statistical analyses such as $p$ value, $F$ value, determination coefficient $\left(\mathrm{R}^{2}\right)$, predicted determination coefficient $\left(\mathrm{R}^{2}\right.$ Pred. $)$, adjusted determination coefficient $\left(\mathrm{R}^{2}{ }_{\text {adj }}\right)$ and coefficient of variance (C.V) to analyze the statistical significance of the model. The generated data were applied for plotting response surfaces after fitting the data to the models.

\section{RESULTS AND DISCUSSION}

\subsection{Optimization of pectin yield $(\%)$ through response surface methodology with the BBD}

Significant factors used in ultrasound-assisted treatment including solid/liquid ratio, $\mathrm{pH}$ values of solvent, sonication time and extraction temperature, were optimized using BBD to maximize pectin yield of pomelo peels. The numbers of experiments required to investigate the above four parameters at three level were 27 using BBD (Table 2). Based on the treatment conditions formulated, the highest pectin yield was $13.34 \%$ after extraction of pomelo peels under the condition of the solid/liquid ratio of $1 / 40, \mathrm{pH}$ values of 1.5 , sonication time of $40 \mathrm{~min}$ and extraction temperature of $80^{\circ} \mathrm{C}$, while the lowest pectin yield was $0.24 \%$ under the condition of the solid/liquid ratio of $1 / 40, \mathrm{pH}$ values of 2.5 , sonication time of $40 \mathrm{~min}$ and extraction temperature of $60^{\circ} \mathrm{C}$. The results indicated that the $\mathrm{pH}$ value of solvent and heating temperature were the most important in the pectin extraction. The lower $\mathrm{pH}$ value of solvent might strongly degrade the cell walls and separate the pectin from other organic compounds, resulting in higher recovery efficiency of pectin. 
Methacanon et al. (2014) also found that the higher yield of pectin was obtained by hydrochloric or nitric acid at $\mathrm{pH} 2.0$ as compared to that obtained at
$\mathrm{pH}$ 3.0. The data were then analyzed through multiple regression analysis to determine the regression coefficients for the equation concerning the relationship between three variables and a response.

Table 2: Box-Behnken experimental design

\begin{tabular}{|c|c|c|c|c|c|}
\hline \multirow[b]{2}{*}{$\begin{array}{c}\text { Run } \\
\text { order }\end{array}$} & \multicolumn{3}{|c|}{ Independent variables } & \multicolumn{2}{|r|}{ Response } \\
\hline & $\begin{array}{r}\text { Solid/Liquid ratio } \\
\left(\mathrm{X}_{1}, \mathrm{~g} / \mathrm{mL}\right)\end{array}$ & pH $\left(\mathbf{X}_{2}\right)$ & $\begin{array}{r}\left(X_{3},\right. \\
\text { min) }\end{array}$ & $\begin{array}{r}\text { Sonication temperature } 1 \\
\left(\mathrm{X} 4,{ }^{\circ} \mathrm{C}\right)\end{array}$ & $\begin{array}{r}\text { Extraction yield } \\
(\%, w / w)\end{array}$ \\
\hline 1 & $1 / 30$ & 1.5 & 40 & 70 & 8.41 \\
\hline 2 & $1 / 50$ & 2 & 40 & 60 & 9.01 \\
\hline 3 & $1 / 40$ & 2 & 30 & 60 & 3.17 \\
\hline 4 & $1 / 50$ & 2 & 30 & 70 & 7.04 \\
\hline 5 & $1 / 40$ & 1.5 & 30 & 70 & 11.45 \\
\hline 6 & $1 / 30$ & 2 & 40 & 80 & 6.04 \\
\hline 7 & $1 / 40$ & 2 & 50 & 80 & 8.57 \\
\hline 8 & $1 / 30$ & 2 & 30 & 70 & 5.17 \\
\hline 9 & $1 / 40$ & 1.5 & 50 & 70 & 11.28 \\
\hline 10 & $1 / 30$ & 2 & 50 & 70 & 6.34 \\
\hline 11 & $1 / 40$ & 2 & 40 & 70 & 5.13 \\
\hline 12 & $1 / 40$ & 2 & 50 & 60 & 3.52 \\
\hline 13 & $1 / 40$ & 2.5 & 40 & 80 & 1.97 \\
\hline 14 & $1 / 50$ & 2 & 50 & 70 & 9.34 \\
\hline 15 & $1 / 30$ & 2 & 40 & 60 & 4.85 \\
\hline 16 & $1 / 40$ & 2 & 40 & 70 & 6.03 \\
\hline 17 & $1 / 50$ & 1.5 & 40 & 70 & 11.35 \\
\hline 18 & $1 / 40$ & 2.5 & 50 & 70 & 1.61 \\
\hline 19 & $1 / 40$ & 2 & 30 & 80 & 8.22 \\
\hline 20 & $1 / 40$ & 1.5 & 40 & 60 & 11.45 \\
\hline 21 & $1 / 50$ & 2 & 40 & 80 & 9.69 \\
\hline 22 & $1 / 40$ & 2 & 40 & 70 & 4.02 \\
\hline 23 & $1 / 30$ & 2.5 & 40 & 70 & 1.22 \\
\hline 24 & $1 / 40$ & 2.5 & 40 & 60 & 0.24 \\
\hline 25 & $1 / 50$ & 2.5 & 40 & 70 & 1.24 \\
\hline 26 & $1 / 40$ & 1.5 & 40 & 80 & 13.34 \\
\hline 27 & $1 / 40$ & 2.5 & 30 & 70 & 1.11 \\
\hline
\end{tabular}

The analysis of variance (ANOVA) was used to evaluate the statistical significance and fitness of the model as presented in Table 3. The results shows that the fitness of model was highly significant because the $\mathrm{p}$ value of the developed model were below 0.0001 (Maran et al., 2013a). The F value and the associated p-value of the lack of fit (2.42 and 0.3281 , respectively) were insignificant due to relative pure error showing that the model equation was good for estimating the pectin yield. The goodness of fit of model was evaluated by the determination coefficient $\left(\mathrm{R}^{2}\right)$, adjusted determination coefficient $\left(\mathrm{R}^{2}{ }_{\text {ddj }}\right)$, predicted determination coefficient $\left(\mathrm{R}^{2}{ }_{\text {Pred }}\right)$ and coefficient of variance (C.V.\%) as shown in Table 3 . The $\mathrm{R}^{2}=0.9299$ showed that the model did not explain only $7.01 \%$ of the total variations. The value of $R^{2}$ Adj of 0.8481 confirmed that the model was highly significant. The higher $\mathrm{R}^{2}$ Adj resulted in the better the degree of correlation between the values which were obtained from the experiments and those predicted from the model. The predicted determination coefficient $\left(\mathrm{R}^{2}\right.$ Pred $)$, a measure of how good the model predicts a response value, was not as close to the adjusted $R^{2}(0.6149$ and 0.8481 , respectively) as one might normally expect, i.e. the difference was more than 0.2. All empirical models were tested by doing confirmation runs Adeq precision measures the signal to noise ratio. A ratio greater than 4 was desirable. The ratio of 11.937 indicates an adequate signal. This model was used to navigate the design space. Meanwhile, the lower value of coefficient of variation (CV) $(7.82 \%)$ was, the higher degree of precision and the greater deal of reliability of the experimental values were (Maran et al., 2013a). 
Table 3: Analysis of variance (ANOVA) for the fitted quadratic polynomial model with experimental and predicted values

\begin{tabular}{|c|c|c|c|c|c|}
\hline Source & Sum of Squares & df & Mean Square & F-value & p-value \\
\hline$\overline{\text { Model }}$ & 351.71 & 14 & 25.12 & 11.37 & $<0.0001$ \\
\hline $\mathrm{X}_{1}$-Solid/liquid ratio & 20.38 & 1 & 20.38 & 9.22 & 0.0103 \\
\hline $\mathrm{X}_{2}-\mathrm{pH}$ & 298.90 & 1 & 298.90 & 135.23 & $<0.0001$ \\
\hline $\mathrm{X}_{3}$ - Sonication time & 1.69 & 1 & 1.69 & 0.7635 & 0.3994 \\
\hline $\mathrm{X}_{4}$ - Sonication temperature & 20.25 & 1 & 20.25 & 9.16 & 0.0105 \\
\hline $\mathrm{X}_{1} \mathrm{X}_{2}$ & 2.13 & 1 & 2.13 & 0.9644 & 0.3455 \\
\hline $\mathrm{X}_{1} \mathrm{X}_{3}$ & 0.3192 & 1 & 0.3192 & 0.1444 & 0.7106 \\
\hline $\mathrm{X}_{1} \mathrm{X}_{4}$ & 0.0650 & 1 & 0.0650 & 0.0294 & 0.8667 \\
\hline $\mathrm{X}_{2} \mathrm{X}_{3}$ & 0.1122 & 1 & 0.1122 & 0.0508 & 0.8255 \\
\hline $\mathrm{X}_{2} \mathrm{X}_{4}$ & 0.0064 & 1 & 0.0064 & 0.0029 & 0.9580 \\
\hline $\mathrm{X}_{3} \mathrm{X}_{4}$ & $5.684 \mathrm{E}-14$ & 1 & $5.684 \mathrm{E}-14$ & $2.572 \mathrm{E}-14$ & 1.0000 \\
\hline $\mathrm{X}_{1}^{2}$ & 4.79 & 1 & 4.79 & 2.17 & 0.1666 \\
\hline $\mathrm{X}_{2}^{2}$ & 0.5433 & 1 & 0.5433 & 0.2458 & 0.6290 \\
\hline $\mathrm{X}_{3}^{2}$ & 1.84 & 1 & 1.84 & 0.8340 & 0.3791 \\
\hline $\mathrm{X}_{4}^{2}$ & 5.27 & 1 & 5.27 & 2.38 & 0.1485 \\
\hline Residual & 26.52 & 12 & 2.21 & & \\
\hline Lack of Fit & 24.50 & 10 & 2.45 & 2.42 & 0.3281 \\
\hline Pure Error & 2.03 & 2 & 1.01 & & \\
\hline Cor Total & 378.24 & 26 & & & \\
\hline$\overline{\mathrm{R}^{2}}$ & & & & & 0.9299 \\
\hline Adjusted $\mathrm{R}^{2}$ & & & & & 0.8481 \\
\hline Predicted $\mathrm{R}^{2}$ & & & & & 0.6149 \\
\hline Adeq Precision & & & & & 11.9372 \\
\hline $\mathrm{CV} \%$ & & & & & 7.82 \\
\hline Predicted pectin yield $(\mathrm{g} / \mathrm{g}$ & ler, $d b)$ & & & & $13.3 \%$ \\
\hline Confirmatory pectin yield ( $\mathrm{g}$ & owder, db) & & & & $12.7 \%$ \\
\hline
\end{tabular}

After multiple regression analysis was carried out on the experimental data, the second-order polynomial equation was formed based on the relationship between the dependent variable and independent variable as follows:

$\mathrm{Y} \%=5.06+1.3 \mathrm{X}_{1}-4.99 \mathrm{X}_{2}+0.375 \mathrm{X}_{3}+1.3 \mathrm{X}_{4}-$ $0.73 \mathrm{X}_{1} \mathrm{X}_{2}+0.2825 \mathrm{X}_{1} \mathrm{X}_{3}-0.1275 \mathrm{X}_{1} \mathrm{X}_{4}+$ $0.1675 \mathrm{X}_{2} \mathrm{X}_{3}-0.04 \mathrm{X}_{2} \mathrm{X}_{4}+0.9479 \mathrm{X}_{1}^{2}+0.3192 \mathrm{X}_{2}^{2}+$ $0.5879 \mathrm{X}_{3}^{2}+0.9942 \mathrm{X}_{4}^{2}$

The p-values were used as a tool to check the significance of each factor and the interaction effects between factors on the pectin yield as shown in Table 3 . The very small $p$-values $(p<0.05)$ showing that the pectin yield was significantly affected by three linear coefficients $\left(\mathrm{X}_{1}, \mathrm{X}_{2}\right.$ and $\left.\mathrm{X}_{4}\right)$. Other coefficients were not significant $(\mathrm{p}>0.05)$.

The optimization of the process variables to maximize pectin yield of the pomelo peel was performed by solving the quadratic models using the studied experimental range of various variables. The predicted value of the responses (predict pectin yield) under optimal conditions (in the range constraint) for the models was $13.3 \%$ under the condition of the solid/liquid ratio of 1:49.6 g/mL, $\mathrm{pH}$ of 1.53 , sonication time of $46.8 \mathrm{~min}$, sonication temperature of $78.3^{\circ} \mathrm{C}$ (Table 3 ). The model was experimentally assessed to confirm the pectin yield of the pomelo peel under optimal condition using the rounded numbers of all factors. As a result, the experimental value (confirmatory pectin yield) was $12.7 \%$ under the experimental conditions of the solid/liquid ratio of $1: 49.5 \mathrm{~g} / \mathrm{mL}, \mathrm{pH}$ of 1.5 , sonication time of $47 \mathrm{~min}$, sonication temperature of $78^{\circ} \mathrm{C}$, which did not significantly differ from the predicted result (Table 3). The extraction yield of pomelo pectin obtained in this study were significantly higher than those obtained by Methacanon et al. (2014), who reported that the pectin yield of pomelo peel was in a range of $8.32-11.06 \%$.

\subsection{Effect of individual variable on pectin yield}

\subsubsection{Effect of solid/liquid ratio}

The extraction yield of pectin obtained at different solid/liquid ratio (1/30-1/50) are given in Figs. 2ac. From the results, the pectin extraction yield was 
the highest when treated at the solid/liquid ratio of 1/49.6. Thus, the plant material in presence of high added solvent (citric acid) was efficiently absorbed microwave energy and easily swollen, which promoted the contact surface area between the plant matrix and the solvent and released higher amounts of pectin.

\subsubsection{Effect of $p H$}

The effect of $\mathrm{pH}$ on pectin extraction yield were evaluated using a range of $\mathrm{pH}$ from $1.5-2.5$ and the results are given in Figs. $2 \mathrm{a}, 2 \mathrm{~d}$ and $2 \mathrm{e}$. The results
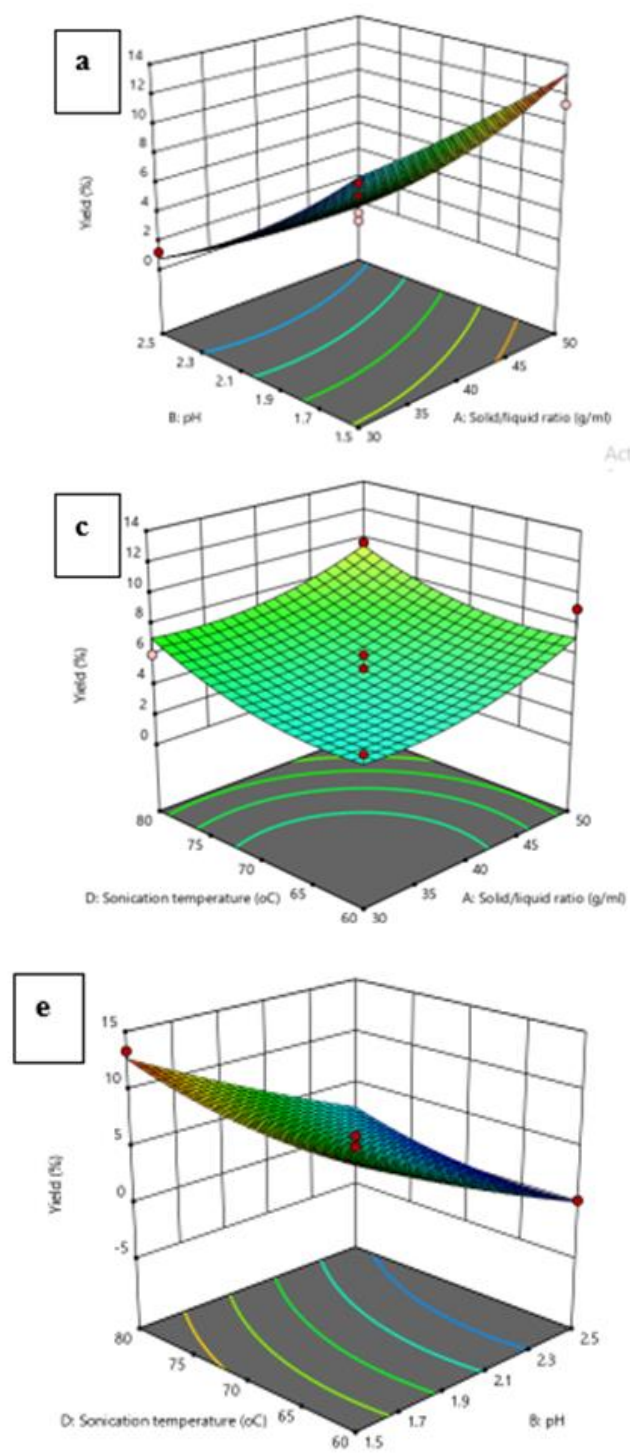

indicated that the extraction yield of pectin significantly decreased with increasing $\mathrm{pH}$ values. The previous study found that the molecular weight of pectin was reduced at low $\mathrm{pH}$ and partially solubilized from plant tissues without any degradation, which was then easily recovered by precipitation (Faravash and Ashtiani 2007). As a result, the extraction at $\mathrm{pH}$ of 1.53 recovered the highest pectin because the acid was considered to degrade cell wall constituents and separate cellular contents for easier extraction. Methacanon et al. (2014) also reported that the extraction of pectin with lower $\mathrm{pH}$ gave significantly higher yield than that with higher $\mathrm{pH}$.
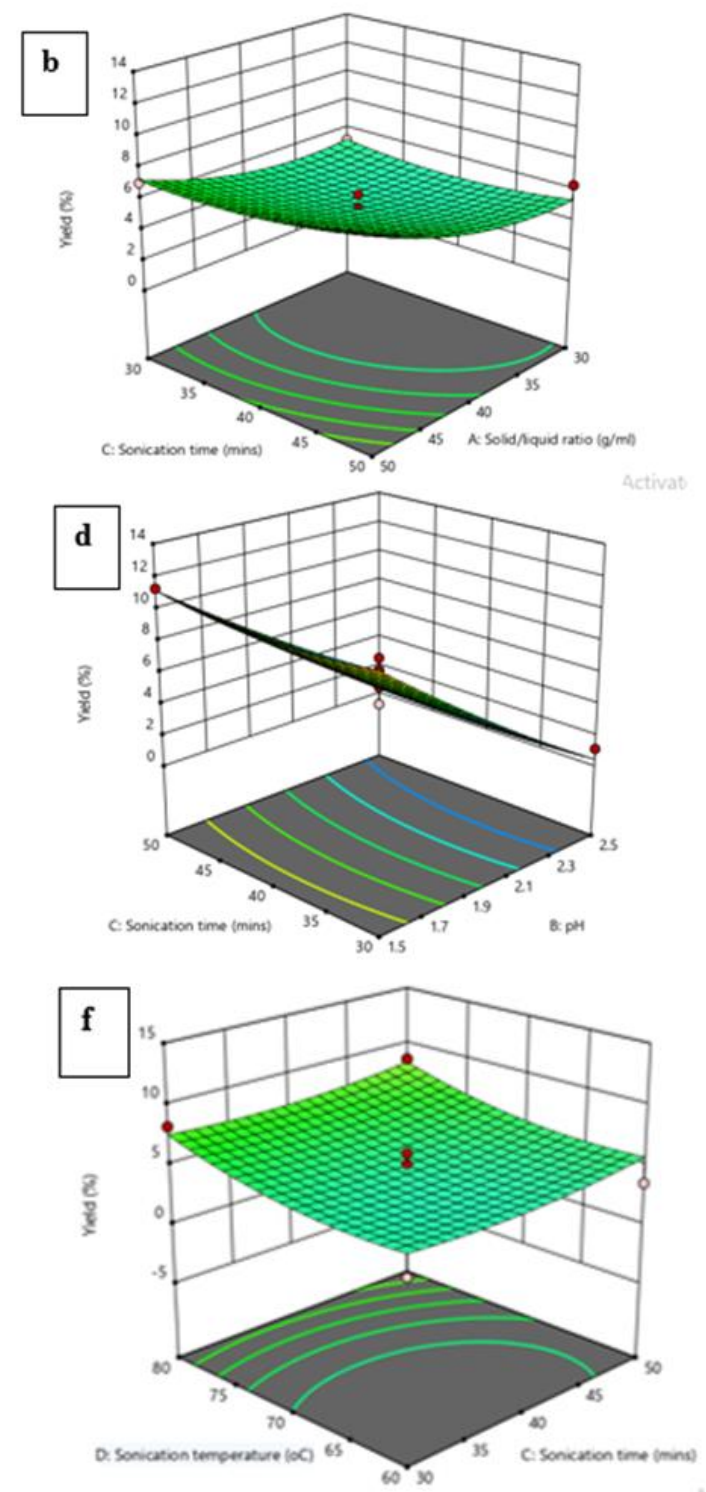

Fig. 2: Effect of process variables on the pectin yield 


\subsubsection{Effect of sonication time}

A range of sonication time of 50 - 50 min was used in this study to investigate the most appropriate sonication time for pectin extraction. As shown in Fig. 2 , the extraction yield of pectin rapidly increased when increasing extraction time. The yield was the highest at $46.8 \mathrm{~min}$ and then decreased slowly (Figs. $2 \mathrm{~b}, 2 \mathrm{~d}$ and $2 \mathrm{f}$ ). This phenomenon could be explained by the fact that the thermal energy was accumulated within extraction solution by the microwave energy absorption and promoted the dissolution process of pectin into solution until $46.8 \mathrm{mins}$ and then decreased the yield gradually. Whereas, too long sonication time may lead to degradation of pectin chain molecules, thus negatively affecting pectin extraction rate (Maran et al., 2013b).

\subsubsection{Effect of sonication temperature}

The extraction efficiency of pectin was improved by increasing sonication temperature from $60-80^{\circ} \mathrm{C}$ (Fig. 2c, e-f). The penetration of solvent into the plant matrix was increased with increase in sonication temperature. The higher temperature also delivered efficiently the solvent to materials through molecular interaction with the electromagnetic field and the energy was rapidly transferred to the solvent and matrix, which allow to extract the pectin easily (Yan et al., 2010). Moreover, the plant cells were ruptured because of the sudden temperature rise and increased internal pressure inside the cells of plant sample. The pectin within the plant cells was released into the surrounding solvents because of the destruction of sample surface by microwave irradiation and increased the extraction yield (Zhang et al., 2008).

\section{CONCLUSION}

In this study, the optimal extraction conditions for pectin extraction were at solid/liquid ratio of 1:49.6 $\mathrm{g} / \mathrm{mL}, \mathrm{pH}$ of 1.53 , sonication time of $46.8 \mathrm{~min}$, sonication temperature of $78.3^{\circ} \mathrm{C}$, corresponding with the maximum pectin yield of $13.34 \%$ using the RSM with the BBD. The confirmatory result obtained at the optimized conditions was $12.73 \%$ under optimal condition using the rounded numbers of all factors, which was not significantly different from the predicted values. As a result, the second-order model was adequate to describe the influence of the selected variables on the extraction yields of pectin.

\section{ACKNOWLEDGMENT}

This research is funded by Vietnam National Foundation for Science and Technology Development
(NAFOSTED) under grant number 106-NN.022016.72 .

\section{REFERENCES}

Bagherian, H., Ashtiani, F. Z., Fouladitajar, A., and Mohtashamy, M., 2011. Comparisons between conventional, microwave-and ultrasound-assisted methods for extraction of pectin from grapefruit. Chemical Engineering and Processing: Process Intensification, 50 (11): 1237-1243.

Bezerra, M. A., Santelli, R. E., Oliveira, E. P., Villar, L. S., and Escaleira, L. A., 2008. Response surface methodology (RSM) as a tool for optimization in analytical chemistry. Talanta, 76(5): 965-977.

Canteri-Schemin, M. H., Fertonani, H. C. R., Waszczynskyj, N., and Wosiacki, G., 2005. Extraction of pectin from apple pomace. Brazilian Archives of Biology and Technology, 48(2): 259-266.

Faravash, R. S. and Ashtiani, F. Z., 2007. The effect of $\mathrm{pH}$, ethanol volume and acid washing time on the yield of pectin extraction from peach pomace. International Journal of Food Science and Technology, 42(10): 1177-1187.

Ferreira, S. C., Bruns, R. E., Ferreira, H. S., et al., 2007. Box-Behnken design: an alternative for the optimization of analytical methods. Analytica Chimica Acta, 597(2): 179-186.

Fox, G., 1984. Zur Wirtschaftlichkeit der Trocknung von Apfeltrester. Confructa Studien. Schönborn, 28(02): 174-182.

Jarvis, M. C., 1984. Structure and properties of pectin gels in plant cell walls. Plant, Cell and Environment, 7(3): 153-164.

Knee, M., Fielding, A. H., Archer, S. A., and Laborda, F., 1975. Enzymic analysis of cell wall structure in apple fruit cortical tissue. Phytochemistry, 14(10): 2213-2222.

Maran, J. P., Manikandan, S., and Mekala, V., 2013a. Modeling and optimization of betalain extraction from Opuntia ficus-indica using Box-Behnken design with desirability function. Industrial Crops and Products, 49: 304-311.

Maran, J. P., Manikandan, S., Thirugnanasambandham, K., Nivetha, C. V., Dinesh, R., 2013b. Box-Behnken design based statistical modeling for ultrasound-assisted extraction of corn silk polysaccharide. Carbohydrate Polymers, 92(1): 604-611.

Methacanon, P., Krongsin, J., and Gamonpilas, C., 2014. Pomelo (Citrus maxima) pectin: Effects of extraction parameters and its properties. Food Hydrocolloids, 35: 383-391.

Paudyal, K. P. and Haq N., 2008. Variation of pomelo (Citrus grandis (L.) Osbeck) in Nepal and participatory selection of strains for further improvement. Agroforestry Systems, 72(3): 195-204. 
Quoc, L. P. T., Huyen, V. T. N., Hue, L. T. N., et al., 2015. Extraction of pectin from pomelo (Citrus maxima) peels with the assistance of microwave and tartaric acid. International Food Research Journal, 22: 1637-1641.

Talmadge, K. W., Keegstra, K., Bauer, W. D., and Alberaheim, P., 1973. The structure of plant cell walls I. The macromolecular components of the walls of suspension-cultured sycamore cells with a detailed analysis of the pectic polysaccharides. Plant physiology, 51(1): 158-173.

Venzon, S. S., Canteri, M. H. G., Granato, D., et al., 2015. Physicochemical properties of modified citrus pectins extracted from orange pomace. Journal of Food Science and Technology, 52(7): 4102-4112.

Yan, M.-M., Liu, W., Fu, Y.-J., Zu, Y.-G., Chen, C.-Y., and Luo, M., 2010. Optimisation of the microwaveassisted extraction process for four main astragalosides in Radix Astragali. Food Chemistry, 119(4): 1663-1670.

Zhang, B., Yang, R., and Liu, C.-Z., 2008. Microwaveassisted extraction of chlorogenic acid from flower buds of Lonicera japonica Thunb. Separation and Purification Technology, 62(2): 480-483. 